\title{
An Immunocapture RT-PCR Procedure Using Apple stem grooving virus Antibodies Facilitates Analysis of Citrus tatter leaf virus from the Original Meyer Lemon Host
}

\author{
Mark E. Hilf, United States Department of Agriculture-Agricultural Research Service, Fort Pierce, FL 34945
}

\begin{abstract}
Hilf, M. E. 2008. An immunocapture RT-PCR procedure using Apple stem grooving virus antibodies facilitates analysis of Citrus tatter leaf virus from the original Meyer lemon host. Plant Dis. 92:746-750.

A magnetic bead-based immunocapture system using polyclonal antiserum against Apple stem grooving virus (ASGV) successfully facilitated polymerase chain reaction (PCR) amplification of sequences from three Citrus tatter leaf virus (CTLV) isolates originally isolated from the citrus host Meyer lemon. Primers designed from a pairwise alignment of genomic sequences of CTLV isolates from lily and from kumquat amplified two nonoverlapping genomic regions of 625 and 1,165 bp (approximately $28 \%$ of the CTLV genome) which were cloned and sequenced. Despite being propagated separately in the glasshouse for more than 40 years, the CTLV sequences from separate Meyer lemon sources were identical but had only approximately $80 \%$ nucleotide identity with the homologous regions of CTLV genomes of isolates from lily and kumquat. Neighbor-joining phylogenetic analysis indicated the CTLV isolates from Meyer lemon were distinct from but more closely related to CTLV from kumquat than from lily, and these CTLV sequences showed equivalent genetic distances from two ASGV isolates.
\end{abstract}

Citrus tatter leaf virus (CTLV) was first identified in California as a latent infection in Meyer lemon trees (Citrus limon hybrid) when Meyer lemon tissue was used to graft inoculate Mexican lime (C. aurantifolia Swingle) and $C$. excelsa Wester plants, which subsequently developed unique leaf symptoms (18). Soon after, CTLV also was found in commercial Meyer lemon trees in Florida (5). A survey found CTLV in all propagations of Meyer lemon but failed to find the virus in 275 selections of domestic and exotic citrus $(18,19)$. A budunion incompatibility with subsequent tree decline was observed with young Satsuma mandarin trees (C. unshiu Marcow.) budded on the hybrid trifoliate orange rootstock Troyer citrange (Poncirus trifoliata (L.) Raf. $\times C$. sinensis Pers.) after trees were infected by graft inoculation with CTLV-infected Meyer lemon tissue (4). In general, CTLV infection is symptomless in the majority of citrus cultivars and no vector species has been implicated in the spread of the virus (7).

Corresponding author: M. E. Hilf E-mail: Mark.Hilf@ars.usda.gov

Mention of a trade name, proprietary product, or specific equipment does not constitute a guarantee or warranty by the United States Department of Agriculture and does not imply approval to the exclusion of other products that may also be suitable.

Accepted for publication 3 January 2008.

doi:10.1094/PDIS-92-5-0746

This article is in the public domain and not copyrightable. It may be freely reprinted with customary crediting of the source. The American Phytopathological Society, 2008.
Serological cross-reactivity (20) and similar genome organizations $(16,20)$ suggested that CTLV should be considered an isolate of Apple stem grooving virus (ASGV), which is the type member of the Capillovirus genus in the family Flexiviridae (1). Two complete CTLV genomic sequences have been determined, one of an isolate from kumquat (Fortunella spp.) in Taiwan (GenBank accession AY646511) and one from lily in Japan (16). Phylogenetic analysis of amplified genomic fragments from the predicted polyprotein (open reading frame $[\mathrm{ORF}] 1$ ) and one from the p36 gene (ORF 2) indicated that CTLV from different citrus cultivars could be more similar to isolates of ASGV from apple and related hosts than to other CTLV isolates (14).

As of 2004, Swingle citrumelo (P. trifoliata (L.) Raf. $\times$ C. paradisi Macfad.) and Carrizo citrange, both trifoliate hybrid rootstocks susceptible to the CTLV-induced budunion incompatibility, comprised 46 and $20 \%$, respectively, of rootstocks used in commercial citrus acreage in Florida (3). Given this large acreage of susceptible rootstocks, the reported genetic variability of CTLV from different citrus and noncitrus hosts, and the historical significance of Meyer lemon as the first reported host of CTLV, work was undertaken to develop molecular genetic data on CTLV from Meyer lemon, to determine its relatedness to other CTLV isolates, and to provide data for the development of diagnostic reagents.

\section{MATERIALS AND METHODS}

Virus history and propagation. Three propagations of CTLV, originally derived from Meyer lemon sources in Florida, were analyzed. Isolate FS 45 was recovered from a Meyer lemon tree in a commercial grove near Winter Haven, FL in 1964. This isolate was graft transmitted to and has been maintained in citrus in the glasshouse since this time. Isolates CTLV3 and CTLV-5 were obtained from the same Meyer lemon tree from a commercial grove near Ruskin, FL in 1964. The current cultures of these two isolates were derived from different local lesions obtained from Red Kidney Bean (Phaseolus vulgaris L.) as part of a sequence of mechanical transmissions made to citrus and herbaceous hosts (Fig. 1). For over 40 years, the three isolates have been maintained in the greenhouse by graft transmission to citrus hosts. FS 45 currently is propagated in sour orange (C. aurantium L.) and CTLV-3 and CTLV-5 both are maintained in $C$. macrophylla Wester.

Virus extraction and immunocapture. Because of its successful use in analysis of Citrus tristeza virus (CTV) $(8,9)$, immunocapture was used for analysis of CTLV isolates from Meyer lemon. For virus extraction, approximately $0.5 \mathrm{~g}$ of expanding flush tissue was pulverized in extraction buffer (0.15 M sodium phosphate, $\mathrm{pH} 7.4$, and $5 \%$ sucrose, wt/vol) for $20 \mathrm{~s}$ using a KLECO pulverizer (Garcia Manufacturing, Visalia, CA). Samples were centrifuged for $10 \mathrm{~min}$ at $10,000 \times g$ to pellet plant debris. Samples were used immediately or stored at $4^{\circ} \mathrm{C}$ for no more than $48 \mathrm{~h}$.

Immunocapture of CTLV virions was done by incubating $500 \mu \mathrm{l}$ of CTLV extract with $20 \mu \mathrm{l}$ of magnetic beads coated with sheep anti-rabbit immunoglobulin G (Invitrogen, Carlsbad, CA) which had been reacted with rabbit anti-ASGV polyclonal antiserum (STA Laboratories, Longmont, $\mathrm{CO}$ ) according to the manufacturer's instructions. Anti-ASGV antiserum was used because it is commercially available and prior testing in plate-based enzyme-linked immunosorbent assays (ELISA) in our lab showed that this antiserum could distinguish CTLV-infected from uninfected citrus (data not presented). This reaction was incubated with slow rotation at room temperature for 1 to $2 \mathrm{~h}$. Beads were washed two to three times with extraction buffer to remove unattached antibodies. Viruscoated beads were suspended in $20 \mu \mathrm{l}$ of extraction buffer and used immediately for reverse transcription or stored at $4^{\circ} \mathrm{C}$.

Reverse transcription-polymerase chain reaction amplification, molecular cloning, and sequencing of CTLV cDNA. 
cDNA was synthesized by reverse transcription (RT) using random primers to prime synthesis from template RNA in virions attached to beads as reported previously for CTV $(8,9)$. Primers for polymerase chain reaction (PCR) were designed from a pairwise local alignment of the genomic sequences of a CTLV isolate from lily (CTLV-L) (16; GenBank accession D16681), and of isolate 'Kumquat 1' from kumquat (GenBank accession AY646511), which was designated CTLV$\mathrm{K}$ for this study. For PCR, $3 \mu \mathrm{l}$ of cDNA were used in a $50-\mu$ l reaction volume with final concentrations of $0.16 \mathrm{mM}$ dNTPs, $1.5 \mathrm{mM} \mathrm{MgCl}_{2}, 0.4 \mathrm{mM}$ each of the forward and reverse primers, and $1 \times$ buffer (Promega Corp., Madison, WI) and amplified for 30 cycles at $94^{\circ} \mathrm{C}$ for $45 \mathrm{~s}, 45^{\circ} \mathrm{C}$ for $30 \mathrm{~s}$, and $72^{\circ} \mathrm{C}$ for $80 \mathrm{~s}$. Reactions were incubated at $72^{\circ} \mathrm{C}$ for an additional $10 \mathrm{~min}$ and stored at $4^{\circ} \mathrm{C}$. An aliquot of each reaction $(10 \mu \mathrm{l})$ was analyzed on $1.5 \%$ agarose gels run in Tris-acetate-EDTA buffer and DNA was visualized with ethidium bromide.

Amplified DNAs were cloned using standard molecular biology protocols and sequencing was performed using an Applied Biosystems 3730 model sequencer at the USHRL Genomics Facility, Fort Pierce, FL.

Sequence characterization and phylogenetic analysis. Primer sequences were removed from cloned Meyer lemon CTLV sequences before analysis. Optimal local sequence alignments were performed with the LALIGN program in the Biology Workbench, San Diego Supercomputer Center, University of California, San Diego. Multiple sequence alignments were performed with ClustalX (17). Genetic distance calculations (p-distances), neighbor-joining (NJ), and maximum parsimony (MP) analyses were performed using programs in the MEGA 3.1 analysis package (12). MP analysis was performed with 1,000 bootstrap replicates using the nearest neighbor interchange algorithm for branch swapping. NJ analysis was performed using the Kimura 2-parameter substitution model with 1,000 bootstrap replicates as a test of phylogeny.

\section{RESULTS}

Immunocapture-RT-PCR of amplicons from CTLV found in Meyer lemon. Based on reports of serological crossreactivity of CTLV when probed with antiASGV polyclonal antibodies (20), a magnetic bead-based immunocapture protocol similar to that developed for analysis of CTV $(8,9)$ was devised using anti-ASGV rabbit polyclonal antibodies.

Seven primer pairs (Table 1) designed from a pairwise alignment of the CTLV-K and CTLV-L genomes were tested for their ability to amplify overlapping cDNAs from randomly primed cDNA reverse transcribed from immunocaptured virions of the FS 45, CTLV-3, and CTLV-5 isolates. The genomic positions of the overlapping regions targeted for amplification are shown in Figure 2. Using the conditions for PCR outlined in Materials and Methods, primer pairs for amplicons 1 and 5 produced products of the expected size from the three Meyer lemon CTLV isolates tested (Fig. 3), whereas no product was

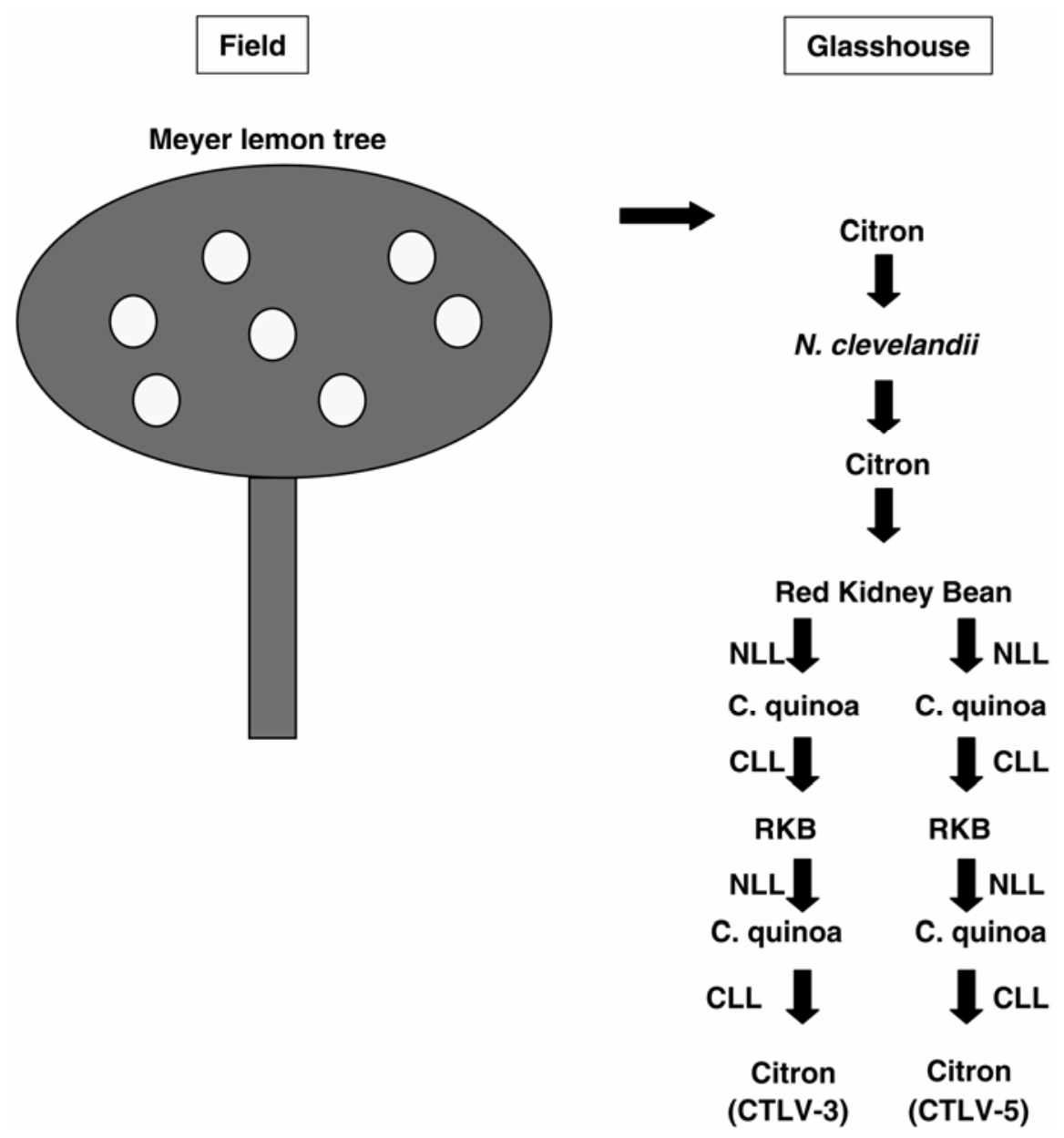

Fig. 1. Schematic outline of host passages performed to obtain current cultures of Citrus tatter leaf virus (CTLV)-3 and CTLV-5. Mechanical transfer of virus was via necrotic local lesions (NLL) and chlorotic local lesions by (CLL). Citron is Citrus medica L. and C. quinoa is Chenopodium quinoa Willd.

Table 1. Primers for amplification of Citrus tatter leaf virus (CTLV) sequences from Meyer lemon

\begin{tabular}{|c|c|c|c|c|c|}
\hline $\begin{array}{l}\text { Primer } \\
\text { sense }\end{array}$ & Primer sequence $\left(5^{\prime} \rightarrow 3^{\prime}\right)$ & $\begin{array}{c}\text { Primer } \\
\text { name }\end{array}$ & $\begin{array}{c}\text { Amplicon } \\
\text { name }\end{array}$ & $\begin{array}{l}\text { Genomic } \\
\text { position }^{\text {a }}\end{array}$ & Size $^{b}$ \\
\hline$(+)$ & 5' ACCTTAGAAGTGACAAATCG 3' & $140 \mathrm{~F}$ & 1 & $140-802$ & 662 \\
\hline$(-)$ & 5' ATGCCACTACAGGTGAAAGG 3' & $802 \mathrm{R}$ & & & \\
\hline$(+)$ & 5' GGCCTTTCACCTGTAGTGGCA 3' & $781 \mathrm{~F}$ & 2 & $781-1,832$ & 1,051 \\
\hline$(-)$ & 5' GGNRTTTRACTTCTTCYGGT 3' & $1832 \mathrm{R}$ & & & \\
\hline$(+)$ & 5' TTGATCARGGCCAGRAGATTYAG 3' & $1539 \mathrm{~F}$ & 3 & $1,539-2,570$ & 1,031 \\
\hline$(-)$ & 5' CYTCCATRAAGGTTCCATCAATC 3' & $2570 \mathrm{R}$ & & & \\
\hline$(+)$ & 5' TCAAAAGAATGTTCATWAGTCC 3' & $2442 \mathrm{~F}$ & 4 & $2,442-3,533$ & 1,091 \\
\hline$(-)$ & 5' CAARAATTGATTTGAGAGACC 3' & 3533R & & & \\
\hline$(+)$ & 5' CTCATGATTTGTTTATAATGC 3' & $3318 \mathrm{~F}$ & 5 & $3,318-4,524$ & 1,206 \\
\hline$(-)$ & $5^{\prime}$ CTCAARTACCAYCCACAGAAC $3^{\prime}$ & $4524 \mathrm{R}$ & & & \\
\hline$(+)$ & 5' GACATGTGCTCMYTGAGCTCTC 3' & $4397 \mathrm{~F}$ & 6 & $4,397-5,431$ & 1,034 \\
\hline$(-)$ & 5' CTCACAGCCRCTRATAGCCTG 3' & $5431 \mathrm{R}$ & & & \\
\hline$(+)$ & $5^{\prime}$ CCACAGTATGAACAGGACACKG 3' & $5287 \mathrm{~F}$ & 7 & $5,287-6,496$ & 1,209 \\
\hline$(-)$ & 5' TAGAGTGGACAAACTCTAGAC 3' & $6496 \mathrm{R}$ & & & \\
\hline
\end{tabular}

${ }^{a}$ Genomic positions refer to genomes of CTLV from kumquat (GenBank accession AY646511) and lily (GenBank accession D16681).

b Expected size of correctly amplified DNA. (results not shown). Both amplicon 1 and ORF1 (Fig. 2) which codes for the large viral polyprotein. Amplicon 1 is derived from a sequence which encodes amino acids near the amino terminus of the polyprotein whereas amplicon 5 is derived from a sequence nearer the carboxy termi- obtained with primer pairs 2, 3, 4, 6, and 7 
nus and encodes for amino acids associated with RNA-dependent-RNA-polymerase activity (16).

Analysis of amplicon-1 sequences from Meyer lemon CTLV. In all, 10 cDNA clones of amplicon 1 were obtained each for the FS 45, CTLV-3, and CTLV-5 isolates, and a consensus sequence for each isolate was derived from a multiple alignment of the sequences of these 10 clones. Nucleotide identities were derived from pairwise sequence comparisons (Table 2, right of the diagonal) and genetic distances (Table 2, p-distances, left of the diagonal) for the Meyer lemon CTLV consensus sequences and the homologous regions from the genomic sequences of two ASGV isolates: isolate 'South Korea' from a pear tree in South Korea (GenBank accession AY596172) and referred to here as ASGV-SK, and isolate P-209 from apple in Japan (20; GenBank accession D14995); and CTLV isolates CTLV-K and CTLV-L. Pairwise comparisons of amplicon 1 sequences from FS 45, CTLV-3, and CTLV-5 showed 99.5 to $100 \%$ nucleotide identity and correspondingly small genetic distances (p-distances) of 0.00 to 0.005 (Table 2). In contrast, these three sequences were equally dissimilar to the four other capillovirus sequences, with approximately $82,83,83$, and $82 \%$ nucleotide identity with P-209, CTLV-L, CTLV-K, and ASGV-SK, respectively. The genetic distances between the FS 45, CTLV-3, and CTLV-5 sequences and the others ranged from 0.168 for CTLV-K to 0.186 for P-209 (Table 2). This data suggests that the Meyer lemon CTLV isolates are most similar to the CTLV-K isolate from kumquat.

Both MP and NJ phylogenetic analysis were performed on these sequences. Tree topology was similar for both methods; therefore, only the results of the NJ analysis are presented. The unrooted tree derived from $\mathrm{NJ}$ analysis of the indicated sequences using the Kimura 2-parameter model of nucleotide substitution is shown in Figure 4A. As expected from the small genetic distances, the CTLV sequences from Meyer lemon cluster together with strong bootstrap support. CTLV-K is grouped with these sequences and, even though the bootstrap support is only $53 \%$, the phylogenetic data for amplicon 1 provides further evidence that the CTLV sequences from Meyer lemon are distinct and most closely related to CTLV-K from kumquat.

Analysis of amplicon 5 sequences from Meyer lemon CTLV. Because amplicon 1 sequences for the three Meyer lemon CTLV isolates were identical, amplicon 5 cDNA was cloned and sequenced only for CTLV-5. Ten cDNA clones were sequenced and a consensus was created from a multiple alignment of these cloned sequences. Percent nucleotide identities and genetic distances calculated for the CTLV-5 amplicon 5 consensus sequence and the other sequences are presented in

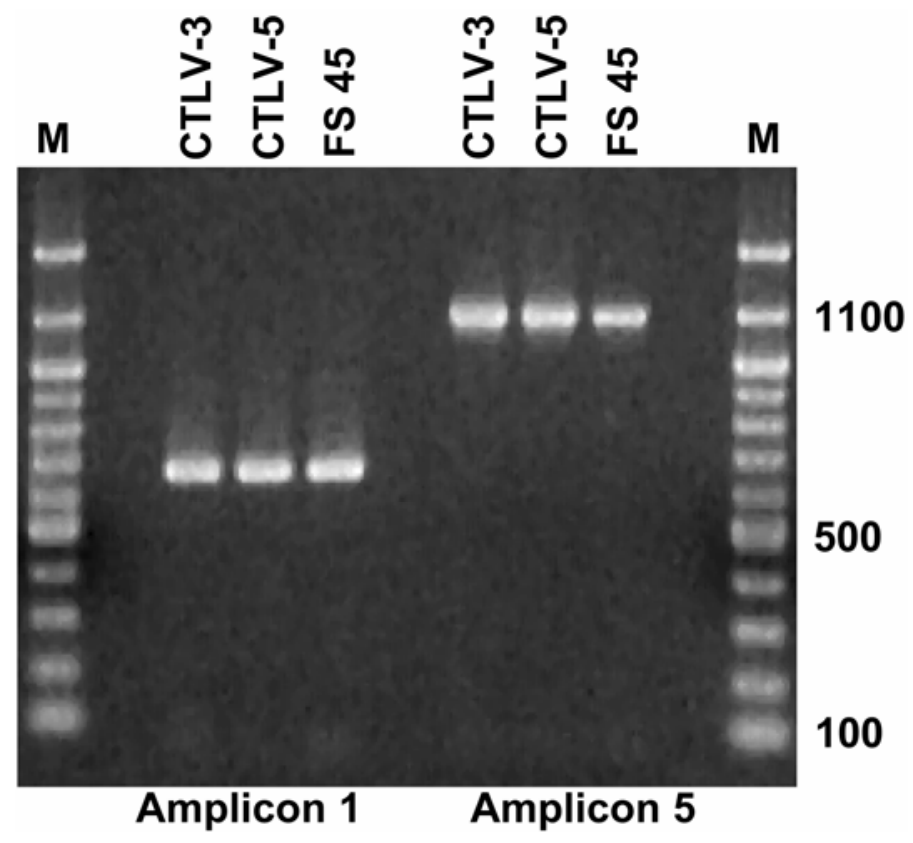

Fig. 3. Agarose gel analysis of amplicons 1 and 5 derived from Meyer lemon Citrus tatter leaf virus (CTLV) isolates. Lanes marked ' $\mathrm{M}$ ' show DNA size markers in 100-bp increments. Numbers on the right of the figure indicate the size of the marker DNA immediately to the left. Lanes 1, 2, and 3 show amplicon 1 and lanes 4, 5, and 6 show amplicon 5 from CTLV-3, CTLV-5, and FS 45, respectively.

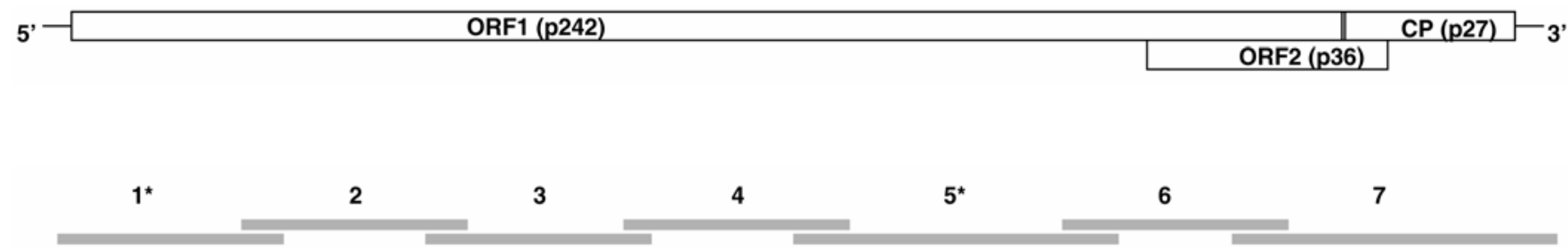

Fig. 2. Genomic locations of overlapping Meyer lemon Citrus tatter leaf virus amplicons proposed for amplification with primer pairs indicated in Table 1. Asterisks indicate regions successfully amplified. The $5^{\prime}$ and $3^{\prime}$ termini and proposed open reading frame (ORF)1 (p242), ORF2 (p36), and capsid protein (CP) genes are indicated as in Ohira et al. (16).

Table 2. Percent nucleotide identities (right of the diagonal) and genetic distances (left of the diagonal in italics) from alignment of Meyer lemon Citrus tatter leaf virus (CTLV) amplicon 1 sequences and the homologous regions from indicated Apple stem grooving virus (ASGV) and CTLV isolates

\begin{tabular}{|c|c|c|c|c|c|c|c|}
\hline Virus isolate & ASGV-SK & CTLV-L & CTLV-K & P-209 & $\mathrm{FS45}^{\mathrm{a}}$ & CTLV-3 ${ }^{b}$ & CTLV-5 \\
\hline ASGV-SK & & 79.8 & 78.2 & 81.1 & 81.6 & 81.6 & 81.6 \\
\hline CTLV-L & 0.202 & $\ldots$ & 82.2 & 84.5 & 82.7 & 82.7 & 82.7 \\
\hline CTLV-K & 0.218 & 0.178 & $\ldots$ & 81.1 & 83.2 & 83.2 & 83.0 \\
\hline P-209 & 0.189 & 0.155 & 0.189 & $\ldots$ & 81.4 & 81.4 & 81.8 \\
\hline FS45 & 0.184 & 0.173 & 0.168 & 0.186 & $\ldots$ & 100.0 & 99.5 \\
\hline CTLV-3 & 0.184 & 0.173 & 0.168 & 0.173 & 0.000 & $\ldots$ & 99.5 \\
\hline CTLV-5 & 0.184 & 0.174 & 0.170 & 0.182 & 0.005 & 0.005 & $\ldots$ \\
\hline
\end{tabular}

a GenBank accession no. EF178287.

${ }^{\mathrm{b}}$ GenBank accession no. EF178288.

c GenBank accession no. EF178289. 
Table 3. As with amplicon 1, the amplicon 5 sequence is most similar to the homologous sequence from CTLV-K, with $82.6 \%$ nucleotide identity and a genetic distance of 0.174 , compared with nucleotide identities of 78.1, 79.7, and 81.0, and genetic distances of $0.219,0.203$, and 0.180 for ASGV-SK, CTLV-L, and P-209 sequences, respectively. As seen with the amplicon 1 sequences, NJ analysis grouped the CTLV5 amplicon 5 sequence with CTLV-K with strong (93\%) bootstrap support (Fig. 4B), supporting the phylogenetic findings from analysis of amplicon 1.

\section{DISCUSSION}

The first description of CTLV was as the causal agent of unusual symptoms in sensitive citrus hosts which had been budded with tissue from the symptomless citrus host Meyer lemon, first in California $(4,18,19)$ and shortly thereafter in Florida (5). In the United States, CTLV has been described only from Meyer lemon, even though indexing efforts from several hundred citrus cultivars and selections was done when it was first found $(18,19)$. Outside of the United States, CTLV was found in lily in Japan (10) and in kumquat, a citrus relative, in Taiwan (GenBank accession AY646511), and in several citrus cul- tivars in Japan $(14,15)$. Although no invertebrate vector is known for CTLV (1), the virus is mechanically transmissible between citrus and noncitrus hosts (6); therefore, movement between different host plants could occur by standard horticultural practices such as pruning. This could explain the occurrence of CTLV in the different citrus hosts as well as in lily.

Even though CTLV transmission between citrus and noncitrus hosts has been demonstrated, the genetic data indicate that CTLV isolates from Meyer lemon, kumquat, and lily are distinct, and that Meyer lemon is not likely to be a recent source of the CTLV in kumquat and lily, and vice versa. Phylogenetic analysis showed that CTLV from Meyer lemon and kumquat formed a distinct clade when compared with ASGV isolates and CTLV from lily, suggesting that these CTLV isolates and hosts in the family Rutaceae share a more recent common origin. An earlier study also showed fairly large genetic divergence between CTLV isolates from different citrus hosts (14).

Meyer lemon was introduced into the United States from China in 1908 and vegetative propagations made from these plants then were distributed throughout the United States, with plants appearing in Florida prior to 1920 (13). Although CTLV was not found in Meyer lemon until the early 1960s (18), the virus is thought to have been in the Meyer lemon plants when they were introduced into the United States from China in 1908 (13). In citrus in the United States, it appears that CTLV was

Table 3. Percent nucleotide identities (right of diagonal) and genetic distances (left of diagonal in italics) from alignment of Meyer lemon Citrus tatter leaf virus (CTLV) amplicon 5 sequences and the homologous regions from indicated Apple stem grooving virus (ASGV) and CTLV isolates

\begin{tabular}{lccccc}
\hline Virus isolate & ASGV-SK & CTLV-L & CTLV-K & P-209 & CTLV-5 $^{\mathbf{a}}$ \\
\hline ASGV-SK & $\ldots$ & 83.8 & 79.2 & 79.1 & 78.1 \\
CTLV-L & 0.162 & $\ldots$ & 79.6 & 82.3 & 79.7 \\
CTLV-K & 0.208 & 0.204 & $\ldots$ & 82.0 & 82.6 \\
P-209 & 0.209 & 0.177 & 0.180 & $\ldots$ & 81.0 \\
CTLV-5 & 0.219 & 0.203 & 0.174 & 0.180 & $\ldots$ \\
\hline
\end{tabular}

${ }^{\mathrm{a}}$ GenBank accession no. EF178289.

A

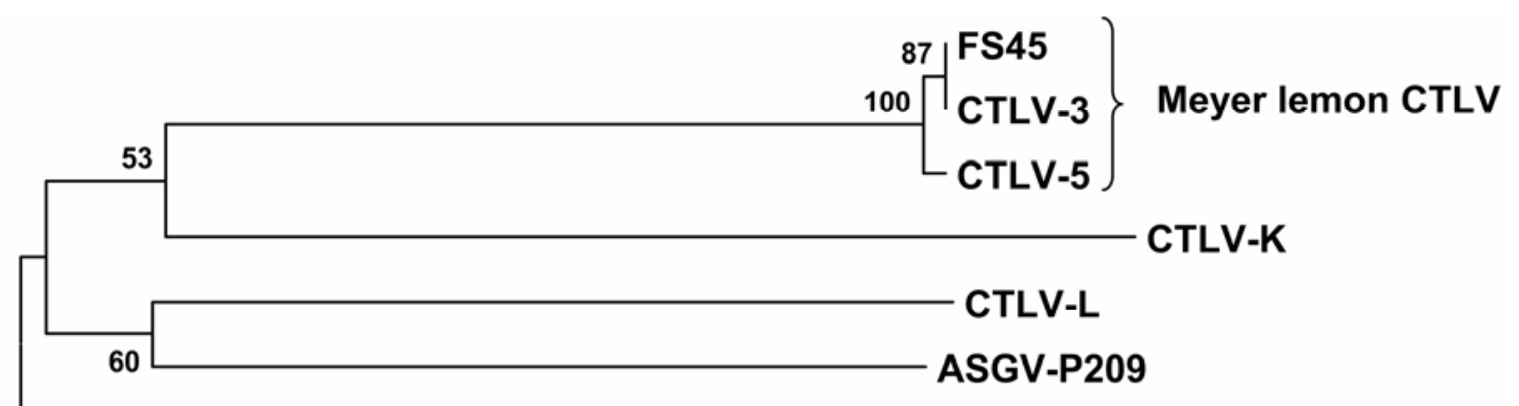

ASGV-SK

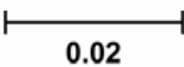

0.02

B
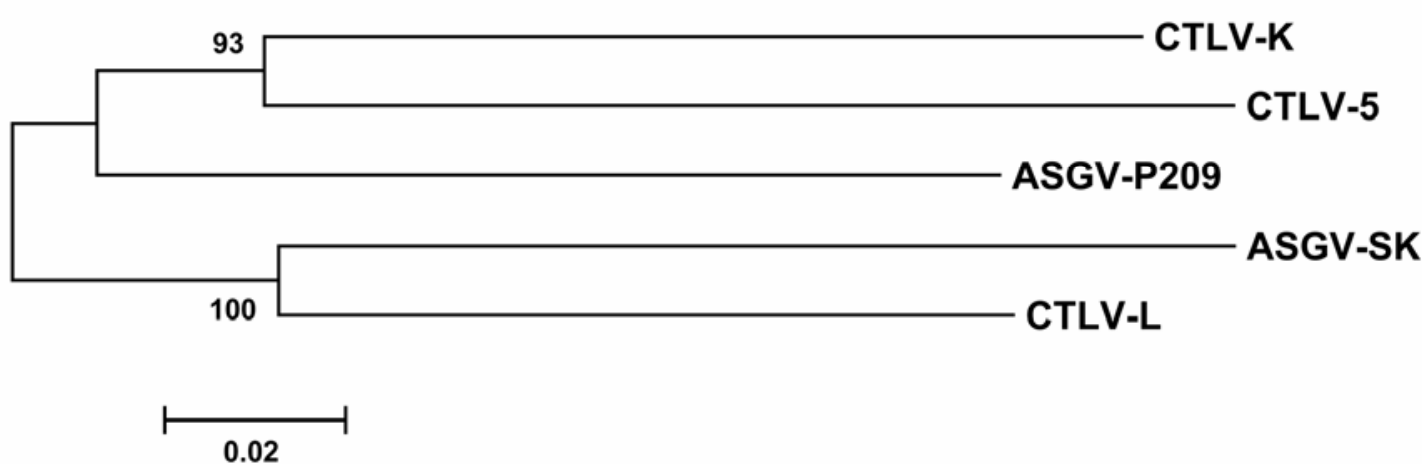

Fig. 4. Phylogenetic relationships of Meyer lemon Citrus tatter leaf virus (CTLV) and other Apple stem grooving virus (ASGV) sequences. Trees are unrooted, neighbor-joining consensus trees of $\mathbf{A}$, amplicon 1 and $\mathbf{B}$, amplicon 5 sequences derived using 1,000 bootstrap replicates. Bootstrap support is indicated at branch points. Brackets to the right in 4A indicate Meyer lemon CTLV sequences. Bar is to scale. 
propagated exclusively in Meyer lemon from 1908 until 1962, when its pathogenic effects were described in other citrus cultivars (18). Remarkably, the CTLV sequences from Florida had different Meyer lemon field origins and different propagation histories in the glasshouse (including different citrus and noncitrus hosts), yet show near identity. The apparent stability of CTLV sequences propagated primarily in Meyer lemon and the degree of dissimilarity between CTLV sequences from Meyer lemon, lily, and kumquat suggests that CTLV was introduced into these different hosts more than 100 years ago.

The current incidence of CTLV in the United States in commercial citrus cultivars such as sweet orange and grapefruit is unknown. However, the increased use of rootstocks derived from trifoliate orange (3) which are susceptible to a CTLVinduced budunion incompatibility (4) suggests a need for more information on the incidence of this virus in commercial citrus in the United States. This study indicates that the immunocapture-RT-PCR procedure using ASGV antisera would be an effective method for detection of CTLV in citrus or other hosts, and it avoids the need for extraction of total nucleic acids as was necessary for previously described PCR methods for detection of CTLV $(2,11)$. Also, because Meyer lemon is the only identified source of CTLV in the United States and was grown in areas such as Florida with large commercial plantings, CTLV found in commercial citrus in the United States likely would be genetically similar to that from Meyer lemon; therefore, data from this study should be useful in the detection of CTLV in commercial citrus in U.S. production areas.

\section{ACKNOWLEDGMENTS}

I thank K. Sims and G. Ingram for their excellent technical assistance in the development of the immunocapture system used in this work and for the cloning and sequencing of CTLV sequences.

\section{LITERATURE CITED}

1. Adams, M. J., Accotto, G. P., Agranovsky, A. A., Bar-Joseph, M., Boscia, D., Brunt, A. A., Candresse, T., Coutts, R. H. A., Dolja, V. V., Falk, B. W., Foster, G. D., Gonsalves, D., Jelkman, W., Karasev, A., Martelli, G. P., Mawassi, M., Milne, R. G., Minafra, A., Namba, S., Rowhani, A., Vetten, H. J., Vishnichenko, V. K., Wisler, G. C., Yoshikawa, N., and Zavriev, S. K. 2005. Virus taxonomy, classification and nomenclature of viruses. Pages 1110-1112 in: 8th Rep. Int. Committee on Taxonomy of Viruses. C. M. Fauquet, M. A. Mayo, J. Maniloff, U. Desselberger, and L. A. Ball, eds. Academic Press, San Diego, CA.

2. Avijit, R., Fayad, A., Barthe, G., and Brlansky, R. H. 2005. A multiplex polymerase chain reaction method for reliable, sensitive and simultaneous detection of multiple viruses in citrus trees. J. Virol. Methods 129:47-55.

3. Bronson, C., Gaskalla, R., and Kessinger, M. 2004. Annual Report, Florida Citrus Budwood Protection Program, Bureau of Citrus Budwood Registration. Winter Haven, FL.

4. Calavan, E. C., Christiansen, D. W., and Roistacher, C. N. 1963. Symptoms associated with tatter-leaf virus infection of Troyer citrange rootstocks. Plant Dis. Rep. 47:971-975.

5. Garnsey, S. M. 1964. Detection of tatter leaf virus of citrus in Florida. Proc. Fla. State Hortic. Soc. 77:106-109.

6. Garnsey, S. M. 1974. Mechanical transmission of a virus that produces tatter leaf symptoms in Citrus excelsa. Pages 137-140 in: Proc. Conf. Int. Organ. Citrus Virol. 6th. IOCV, Riverside, CA.

7. Garnsey, S. M., and Miyakawa, T. 1988. Tatterleaf and citrange stunt. Pages 47-48 in: Compendium of Citrus Diseases. American Phytopathological Society Press, St. Paul, MN.

8. Hilf, M. E., Karasev, A. V., Albiach-Marti, M. R., Dawson, W. O., and Garnsey, S. M. 1999. Two paths of sequence divergence in the Citrus tristeza virus complex. Phytopathology 89:336-342.

9. Hilf, M. E., Mavrodieva, M. A., and Garnsey, S. M. 2005. Genetic marker analysis of a global collection of isolates of citrus tristeza virus: characterization and distribution of CTV genotypes and association with symptoms. Phytopathology 95:909-917.

10. Inouye, N., Maeda, T., and Mitsuhata, K. 1979. Citrus tatter leaf virus isolated from lily. Ann. Phytopathol. Soc. Jpn. 45:712-720.

11. Ito, T., Ieki, H., and Ozaki, K., 2002. Simultaneous detection of six citrus viroids and Apple stem grooving virus from citrus plants by multiplex reverse transcription polymerase chain reaction. J. Virol. Methods 106:235-239.

12. Kumar, S., Tamura, K. and Nei, M. 2004. MEGA3: integrated software for molecular evolutionary genetics analysis and sequence alignment. Brief. Bioinf. 5:150-163.

13. Lee, R. F., Barber, B., Brown, L., Kesinger, M., Garnsey, S., and Schirard, B. 1997. Is Meyer lemon a threat to citrus? Citrus Ind. 75:46-49.

14. Magome, H., Yoshikawa, N., Takahashi, T. and Miyakawa, T. 1997. Molecular variability of the genomes of capilloviruses from apple, Japanese Pear, European pear and citrus trees. Phytopathology 87:389-396.

15. Miyakawa, T., and Matsui, C. 1977. A budunion abnormality of Satsuma mandarin on Poncirus trifoliata rootstock in Japan. Pages 125131 in: Proc. Conf. Int. Organ. Citrus Virol. 7th. IOCV, Riverside, CA.

16. Ohira, K., Namba, S., Rozanov, M., Kusumi, T., and Tsuchizaki, T. 1995. Complete sequence of an infectious full-length cDNA clone of citrus tatter leaf capillovirus: comparative sequence analysis of capillovirus genomes. J. Gen. Virol. 76:2305-2309.

17. Thompson, J. D., Gibson, T. J., Plewniak, F., Jeanmougin, F., and Higgins, D. G. 1997. The ClustalX windows interface: flexible strategies for multiple sequence alignment aided by quality analysis tools. Nucleic Acids Res. 24:48764882.

18. Wallace, J. M., and Drake, R. J. 1962. Tatter leaf, a previously undescribed virus effect on citrus. Plant Dis. Rep. 46:211-212.

19. Wallace, J. M., and Drake, R. J. 1963. New information on symptom effects and host range of the citrus tatter leaf virus. Plant Dis. Rep. 47:352-353.

20. Yoshikawa, N., Imaizumi, M., Takahash, T., and Inouye, N. 1993. Striking similarities between the nucleotide sequence and genome organization of citrus tatter leaf and apple stem grooving capilloviruses. J. Gen. Virol. 74:2743-2747. 